\title{
The simple solution to a complex case
}
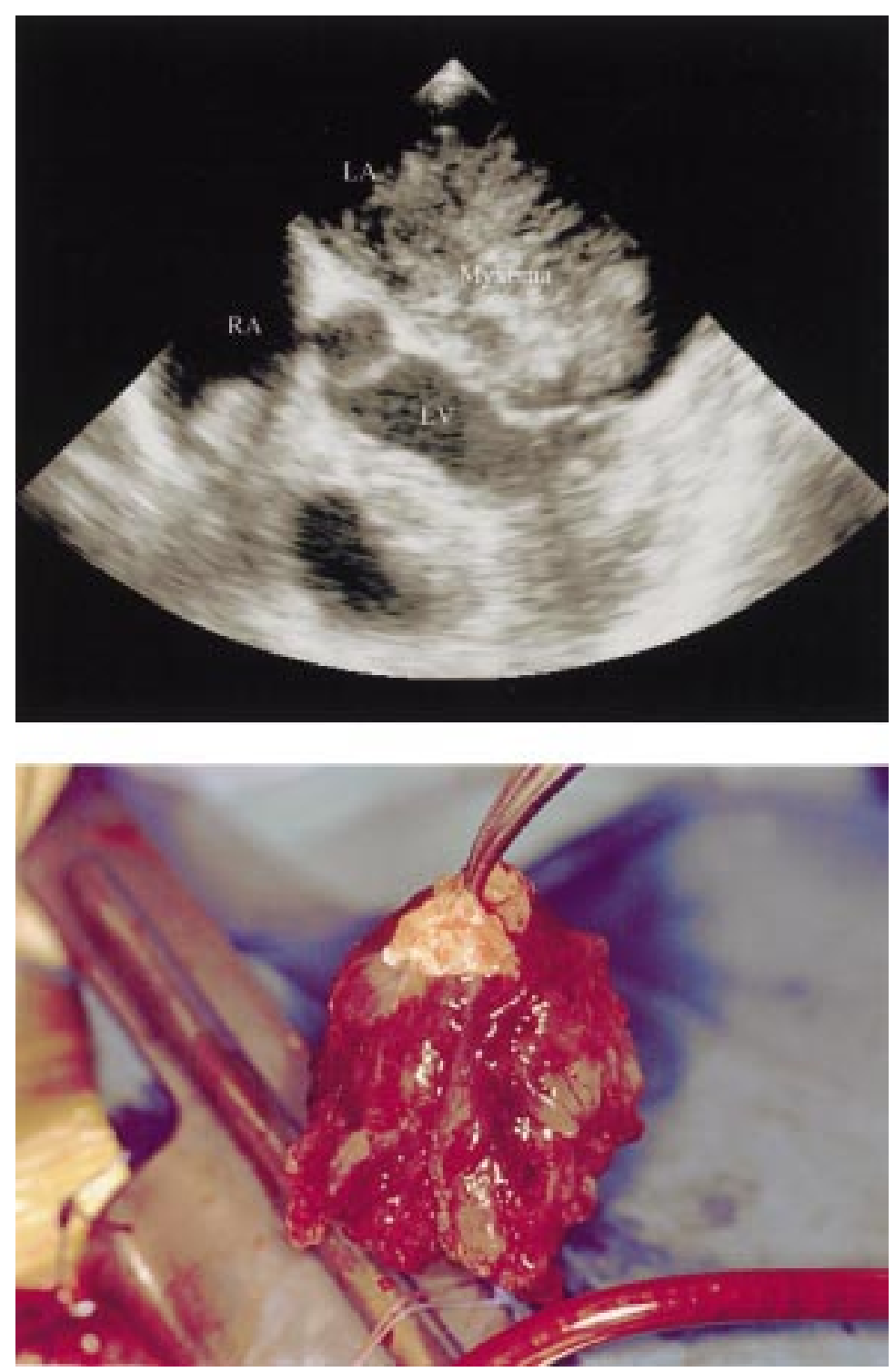

During Spring 1999 this 41 year old woman experienced paraesthesia and difficulties with moving her right arm for about 30 minutes, which improved spontaneously. In August 99 the patient noted a bluish disseminated discoloration over the forefoot and the first digits. She went to her general practitioner who found a moderately raised sedimentation rate and an $M$ component IgG of 2-3 g/l. Bone marrow biopsy and skeletal radiography showed no signs of myeloma.

In December 1999 the patient fainted for a few seconds while taking a shower. Thereafter, she was unable to move her right arm and she complained of paraesthesia in the right arm for several days.

Brain MRI showed disseminated changes, most likely due to small infarcts.

Electrolytes, spinal fluid proteins, polymerase chain reaction for herpes simplex I and II, serology for cytomegalovirus, borrelia, and TBE, and ANA, ANCA, ENA, and RF were all normal. The sedimentation rate was 44 , haemoglobin $104 \mathrm{~g} / \mathrm{l}$, and C-reactive protein $36 \mathrm{mg} / \mathrm{l}$.

Before a planned brain biopsy, it was decided to perform an echocardiogram. In the left atrium a large myxoma, moving forward and backward like seaweed, was discovered. The upper part of the figure shows the transoesophageal echocardiographic appearance (LA=left atrium, $\mathrm{LV}=$ left ventricle, $\mathrm{RA}=$ right atrium).

The patient was operated on and a $6.5 \times 5 \mathrm{~cm}$ myxoma was excised. In the lower part of the image, the myxoma is held by the forceps in the part of the interatrial septum from where it had emanated.

The patient's recovery was uneventful. In retrospect, symptoms suggestive of multiple systemic embolisation in combination with the vague signs of inflammatory disorder could have raised the suspicion for myxoma earlier.

T KÜHME S FRANZÉN Department of Thoracic Surgery, Linköping Heart Centre, University Hospital, SE. 581 85, Linköping, Sweden

E NYLANDER

Department of Clinical Physiology

Correspondence to: Dr T Kühme

Tobias.Kuhme@lin.se 